\title{
ESTUDO PARAMÉTRICO DA INJEÇÃO DE POLÍMEROS EM RESERVATÓRIOS DE PETRÓLEO.
}

\author{
M.S.B. da SILVA ${ }^{1}$, J.L.M. BARILLAS ${ }^{2}$ e T.V.DUTRA JR. ${ }^{3}$ \\ 1,2 e 3 Universidade Federal do Rio Grande do Norte, Programa de Pós-Graduação em Ciência e \\ Engenharia de Petróleo \\ E-mail para contato: socorromarya@gmail.com
}

\begin{abstract}
RESUMO - Osreservatórios de petróleo que retêm grandes quantidades de hidrocarbonetos após a diminuição da sua energia natural são candidatos ao emprego de processos que visam à obtenção de uma recuperação adicional de óleo. $\mathrm{O}$ desenvolvimento de novas técnicas que possibilitem extrair mais deste óleo residual permite aumentar a rentabilidade dos campos petrolíferos e estender sua vida útil. Nesta recuperação adicional são enfrentados diversos problemas, entre os quais o baixo fator de recuperação de óleo associado a uma alta produção de água. Para resolver esses problemas a injeção de solução polimérica é aplicada para atingir uma produção de óleo técnica e economicamente satisfatória. Neste trabalho, foram realizadas simulações variando a porcentagem do polímero utilizado na solução polimérica para analisar o comportamento deste no reservatório. Esta análise tem como finalidade identificar um banco de polímero que tenha uma boa resposta quando aplicado ao reservatório em análise e com baixos custos na operação. Foram realizadas simulações para analisar a influência da injeção de água, solução polimérica e injeção alternada de bancos de água e de solução polimérica, analisando a produção acumulada do óleo e comparando cada situação simulada.
\end{abstract}

\section{INTRODUÇÃO}

Na recuperação de petróleo são enfrentados diversos problemas, entre os quais o baixo fator de recuperação de óleo associado a uma alta produção de água. Dentre as várias dificuldades que afetam a produção do petróleo a partir dos reservatórios, uma em especial, tem a ver com a imiscibilidade e a diferença de viscosidade entre os fluidos presentes na jazida. Quando a água e o óleo (geralmente mais viscoso) escoam ao mesmo tempo através de um meio poroso (reservatório), a água tende a se deslocar em uma velocidade maior que o óleo, no seu curso em direção aos poços produtores. Com isso, ocorrerá a chegada prematura e crescente da água nestes poços, afetando a recuperação final do petróleo.

A fim de resolver esses problemas várias propostas têm sido apresentadas com o intuito de atenuar os danos sobre a recuperação. Esses métodos são chamados de recuperação suplementar. Eles consistem na injeção de produtos que geralmente não estão presentes no reservatório e modificam as 
características do meio poroso. Para reservatórios em que o petróleo não é do tipo "pesado" e possui mobilidade, uma proposta foi à utilização do método convencional de recuperação por injeção de água, porém, aditivada com polímeros hidrossolúveis de elevada massa molar. Mesmo em pequenas concentrações, estes produtos fazem com que a viscosidade da água (fluido deslocante) seja aumentada e aproxime-se da viscosidade do óleo (fluido deslocado). Dessa forma, a solução polimérica injetada no reservatório promoverá um deslocamento uniforme (do tipo pistão), em relação à fase óleo (Babadagli, T, 2005). O resultado é o retardamento da invasão de água nos poços produtores e, portanto, uma maximização da eficiência de recuperação (Zaitoun et. al., 1991; Revista Petro\& Química, 2002).

\subsection{Injeção de água}

A injeção de água (waterflooding) é o método mais comum de injeção de fluidos em reservatórios. Sua popularidade se justifica através da sua disponibilidade, relativa facilidade para operação e boa eficiência em deslocar óleo (Craig, 1993), além de baixo custo.

Porém, devido à razão de mobilidade entre óleo e água, a água não é capaz de deslocar todo o óleo presente no reservatório. A interface óleo-água é extremamente instável e existe uma tendência de formação de canais de escoamento preferenciais (van Meurs\& van der Poel, 1958). A água, ao ser injetada, percorre este canal preferencial, geralmente caracterizado por uma zona mais permeável ou por ser o caminho mais curto entre os poços injetor e produtor. A Figura 1 apresenta o esquema da injeção de água.

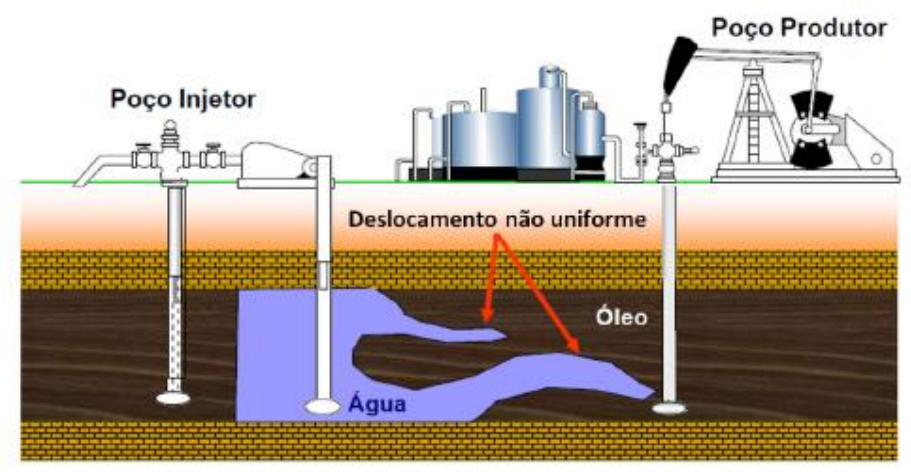

Figura 1 - Representação esquemática do método de recuperação de petróleo mediante injeção de água. Adaptado de (Miranda, 2010).

\subsection{Injeção de polímeros}

A injeção de polímeros tem o objetivo de aumentar a viscosidade da água de injeção e melhorar a razão de mobilidades água/óleo. Com isso, há uma uniformização da frente de avanço, que melhora a eficiência de varrido areal e vertical. Este método visa recuperar o óleo móvel remanescente que a 
injeção de água não deslocou, mas também pode ser aplicado desde o início do desenvolvimento de um reservatório. Além de aumentar a eficiência de varrido, este método busca reduzir a quantidade de água injetada e consequentemente produzida (Rosa 2006). A Figura 2 apresenta o esquema da injeção de polímeros.

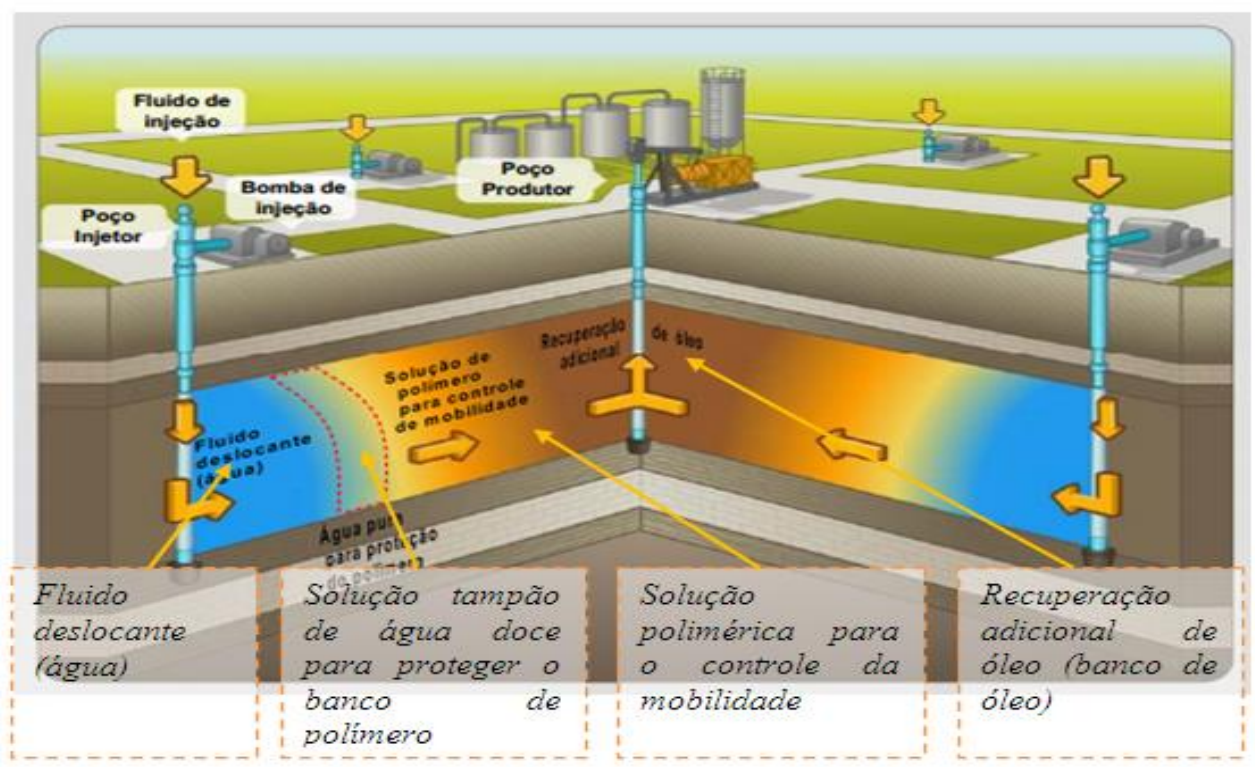

Figura 2 - Esquema da sequência de injeção de polímeros (Lake, 1989).

\subsection{Critérios de seleção para aplicação do método}

Os critérios de seleção são regras para aplicação de um processo de recuperação segundo as características do campo onde se deseja implantar tal método. Apesar das vantagens na aplicação de polímeros, seu uso apresenta limitações que podem ser categorizadas como técnicas, econômicas e de regulamentação legal e cada caso deve ser analisado segundo critérios que envolvem as características dos fluidos, das formações contatadas e das operações envolvidas. A tabela 1 apresenta alguns dos critérios para seleção do método.

O sucesso na recuperação de petróleo através de polímeros é maior para formações homogêneas ou com baixo grau de heterogeneidade. A temperatura é uma das restrições mais severas para a seleção do método. $\mathrm{O}$ reservatório deve estar preferencialmente abaixo de $80^{\circ} \mathrm{C}$. 
Tabela 1 - critérios de seleção para aplicação do método

Critérios $\quad$ Valores e características

\begin{tabular}{|c|c|}
\hline Grau API & $15<^{\circ} \mathrm{API}<40$ \\
\hline Viscosidade do óleo (cp) & $<150$. Preferencialmente $10<\mu \mathrm{o}<100$ \\
\hline Saturação de óleo (\%PV) & $>70$ \\
\hline Tipo de formação & $\begin{array}{l}\text { Preferência arenito, mas pode ser aplicado } \\
\text { em cabonato. }\end{array}$ \\
\hline $\begin{array}{l}\text { Permeabilidade Absoluta } \\
\text { (md) }\end{array}$ & Mínima 20 \\
\hline Profundidade & $<9.000 \mathrm{ft}(2745 \mathrm{~m})$ \\
\hline Temperatura & $\begin{array}{l}\text { Temperaturas mais baixas são melhores } \\
\text { Máximo } 95^{\circ} \mathrm{C} \text {. Melhores }<80^{\circ} \mathrm{C}\end{array}$ \\
\hline Salinidade & $<100.000 \mathrm{ppm}$ \\
\hline Dureza & $<1.000 \mathrm{ppm}$ \\
\hline
\end{tabular}

\section{METODOLOGIA}

Para a realização do estudo proposto, com vistas à análise dos benefícios da injeção desolução polimérica como método de recuperação em comparação com o método convencional de injeção deágua, foiutilizado o simulador comercial STARS (Steam, Thermal and Advanced ProcessReservoir Simulation) que é um simulador térmico - composicional e de processos avançados de reservatório desenvolvido pela CMG (Computer Modeling Group Ltd.).

O modelo utilizado para o estudo foi um reservatório homogêneo, semissintético com características baseadas em reservatórios do Nordeste Brasileiro e está apresentado na Figura 3.

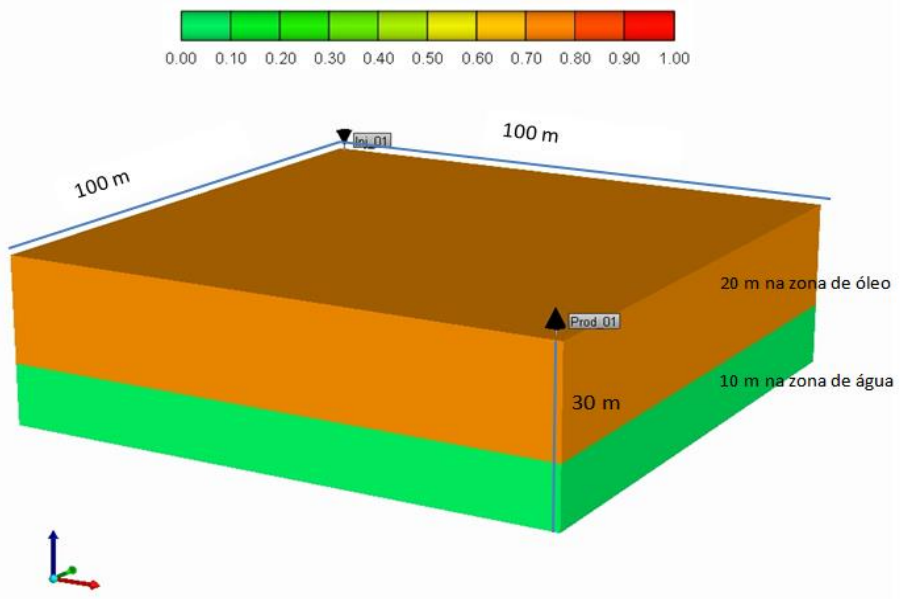

Figura 3 - Modelo composicional do reservatório em 3D com configuração de injeção five-spot. 
A elaboração do modelo de simulação visou à representação de um reservatório que se enquadrasse nos critérios de seleção para aplicação de injeção de polímero, as propriedades do óleo e características geológicas do reservatório foram selecionadas dentro de valores sugeridos na Tabela 1, e estão apresentados na Tabela 2.

Tabela 2 - Principais informações do modelo de simulação

\begin{tabular}{ccc}
\hline Tipo de informação & Parâmetro & Valor \\
& & \\
\hline Propriedades da & Profundidade & $687 \mathrm{~m}$ \\
Formação & Porosidade & 0,23 \\
& Compressibilidade da formação & $30 \times 10^{-5}(1 / \mathrm{psi})$ \\
& Temperatura & $50^{\circ} \mathrm{C}$ \\
Propriedades do & Pressão de referência & $28,5 \mathrm{psi}$ \\
óleo & Viscosidade do óleo & $43\left(\mathrm{cP} @ 50^{\circ} \mathrm{C}\right)$ \\
Propriedades do & Grau API & 28.66 \\
polímero utilizado & Pressão crítica & $29 \mathrm{psi}$ \\
& Temperatura Crítica & $300 \mathrm{~F}$ \\
& Peso molecular & $100001 \mathrm{~b} / \mathrm{lbmol}$ \\
& Densidade & $0.0062 \mathrm{lb} / \mathrm{ft}^{3}$ \\
Condições & Viscosidade & $20 \mathrm{cp}$ \\
operacionais & Vazão máxima no poço injetor & $500\left(\mathrm{~m}^{3} \mathrm{std} / \mathrm{dia}\right)$ \\
& Pressão mínima no poço produtor & $28,5 \mathrm{psi}$ \\
& Pressão máxima no poço injetor & $2500 \mathrm{psi}$ \\
\hline
\end{tabular}

A partir deste modelo foram realizadas as simulações do processo de injeção de solução polimérica. A densidade do polímero utilizado foi de $0,0062 \mathrm{lb} / \mathrm{bbl}$, ou $100 \mathrm{ppm}$. O tamanho do banco de polímero injetado foi de $20 \%$ do volume poroso, e enquadra-se na faixa dos casos mais bem sucedidos (7\% a 33\%) mencionada por (Du e Guan, 2004) em seu trabalho que revisa a técnica de injeção polimérica em escala de campo nos últimos quarenta anos. A solução polimérica utilizada no estudo contém $20 \%$ de polímero e $80 \%$ de água.

As simulações têm duração de vinte anos de produção e foi adotada a estratégia de injetar bancos alternados de solução polimérica com água e injeção contínua de solução polimérica. Os resultados e análises destas simulações em comparação com a produção simulada no mesmo modelo e sob as mesmas condições operacionais, mas com injeção de apenas água de forma contínua durante os 20 anos, podem ser observados na próxima seção. 


\section{RESULTADOS E DISCUSSÃO}

Com o modelo de reservatório descrito na seção anterior, as simulações foram realizadas focando demonstrar os principais impactos decorrentes da injeção de solução polimérica no meio poroso contrapondo à injeção de apenas água. A Figura 4-a apresenta as curvas de produção acumulada da Injeção contínua de solução polimérica com $0 \%, 30 \%, 50 \%, 70 \%$ e 100\% de polímero na solução, com o objetivo de analisar sua eficiência na recuperação do óleo. A Figura 4-b apresenta as curvas de produção acumulada nos processos simulados comparando com a recuperação primária.

a) b)
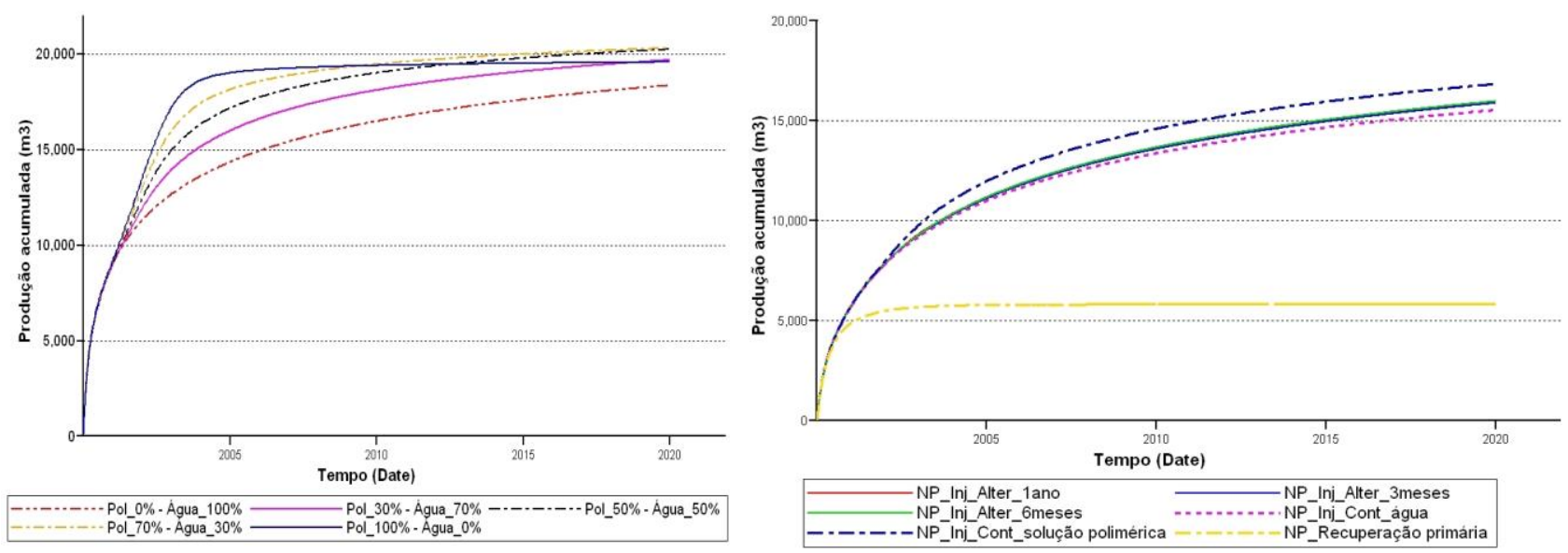

Figura 4- a) - Análise do método com diferentes porcentagens de polímero. b) - Curvas de produção acumulada nos processos simulados comparando com a recuperação primária.

Do gráfico da Figura 4-a, pode-se observar uma maior produção de óleo decorrente dainjeção de polímero, implicando numa maior produção de óleo em relação à injeção de somente água, $0 \%$ de polímero que está apresentado na curva vermelha.É possível observar que a diferença entre os modelos de injeção de água com polímero e apenas com a injeção de água, após 20 anos de projeto, apresenta resultados satisfatórios para o emprego do método.

Do gráfico da Figura 4-b, são apresentadas as curvas de produção acumulada nos processos simulados contínuos e alternados. A curva pontilhada em azul representa a produção acumulada, quando é utilizada a solução polimérica de forma contínua, a qual obteve a melhor produção de óleo no reservatório em estudo.

Observando os mapas de saturação de óleo na Figura 5, é possível ainda, verificar melhores eficiências de varrido areal no caso de injeção de polímeros na Figura 5-a em relação à injeção de água. A Figura 5-a mostra uma saturação de óleo menor próximo ao poço injetor por onde o banco polimérico varreu. A Figura 5-b mostra a saturação de óleo com a injeção de água, e observa-se que a água não consegue ter uma boa recuperação do óleo, deixando boa parte do óleo ainda no reservatório. Vale salientar que nos dois casos o mesmo volume delíquido é injetado no reservatório, com a única diferença que em um dos casos é injetada uma solução polimérica. 
a)

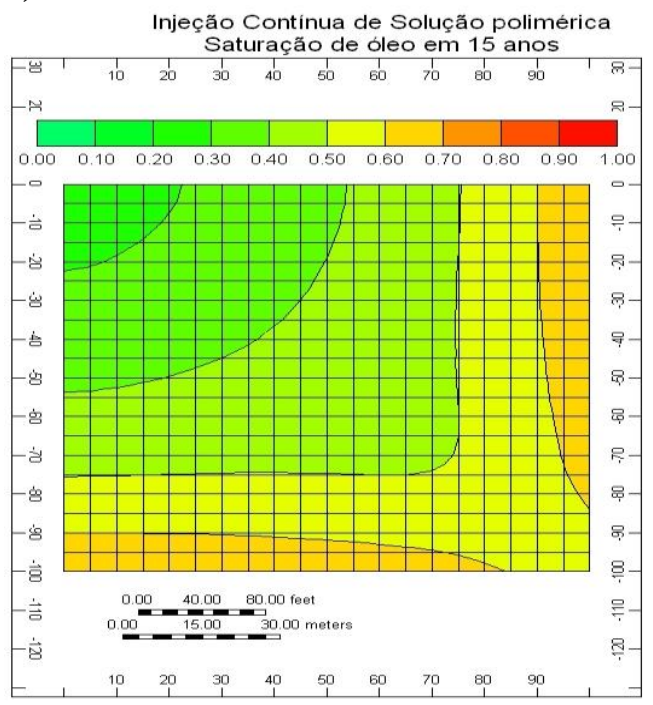

b)

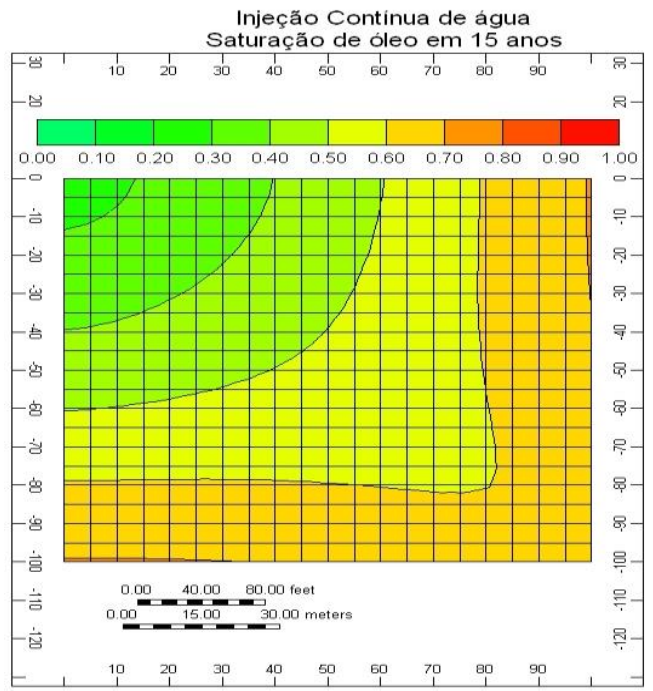

Figura 5 - a) Mapas de saturação de óleo com a injeção de solução polimérica. b) Mapas de saturação de óleo com a injeção de água.

Os mapas de viscosidade da água apresentadas na Figura 6, mostram a viscosidade da água quando é utilizada a solução polimérica na Figura 6-a e a Figura 6-b mostra a viscosidade quando é utilizado apenas água.

a)

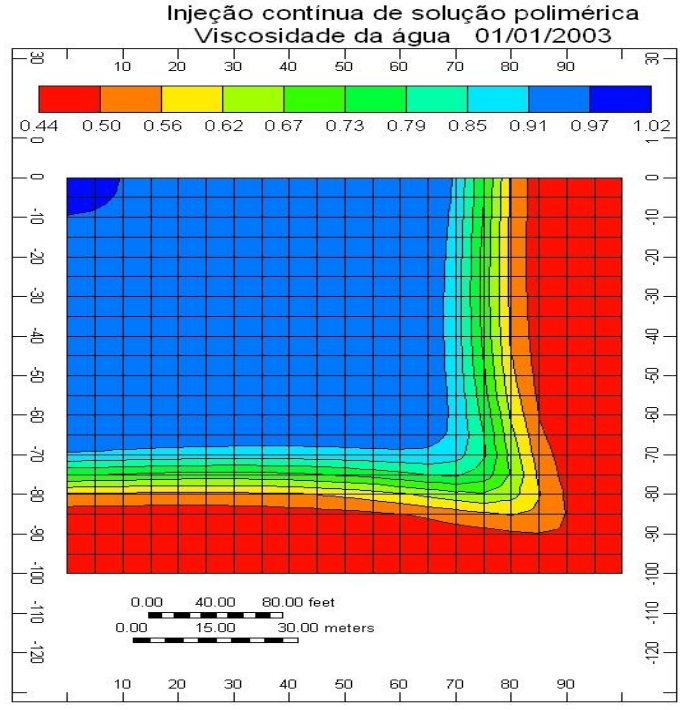

b)

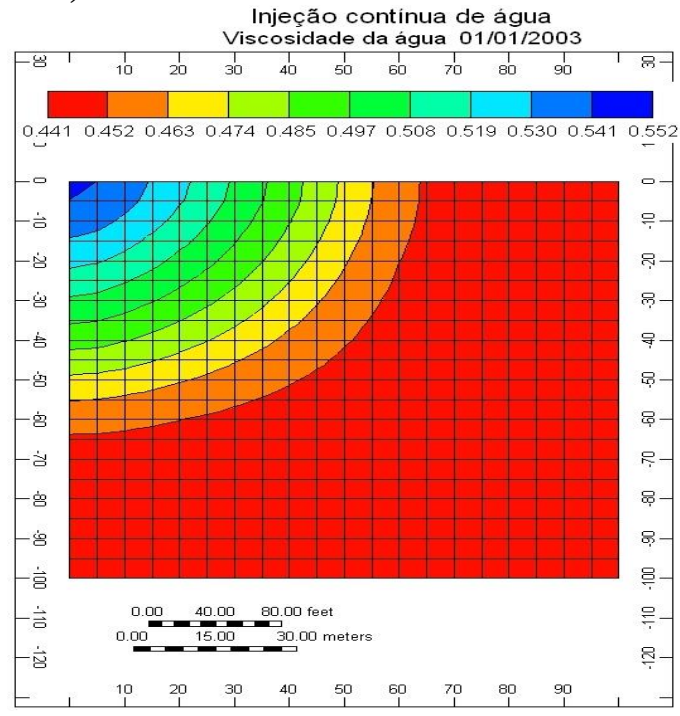

Figura 6 a) - Mapas de viscosidade da água utilizando injeção de solução polimérica. b) Mapas de viscosidade da água utilizando injeção de água. 
A Figura 6-a mostra que em três anos de projeto já é possível observar um deslocamento uniforme no reservatório quando é utilizada a solução polimérica, indicando que o polímero agiu viscosificando à água, assim tendo uma maior eficiência de deslocamento do óleo no reservatório em relação à injeção apenas com água apresentada na Figura 6-b.

\section{CONCLUSÕES}

Com a utilização do método de Injeção de solução polimérica, pode-se concluir que houve um incremento na produção de óleo do reservatório em estudo. O percentual adicional de óleo obtido após a varredura do reservatório com a água foi pequeno indicando que o polímero conseguiu deslocar o óleo de forma mais eficiente dentro do meio poroso. No entanto, o sucesso técnico e econômico da aplicação desta técnica depende das características e propriedades dos fluidos e da formação, que devem se enquadrar nos limites sugeridos nos critérios de seleção.

Os processos simulados, de forma alternadas, apresentaram melhores resultados na produção de óleo com relação à injeção contínua de água, no entanto, a injeção contínua de solução polimérica apresentou melhores resultados para a produção acumulada de óleo.

\section{REFERENCIAS}

BABADAGLI, T.; Mature field development: A review. SPE. 93884, p. 1-20, 2005.

CRAIG, F.F. Jr.;The Reservoir Engineering Aspects of Waterflooding, Monograph series, SPE; 1993.

DU, Y., GUAN, L.;Field-Scale Polymer Flooding: Lessons Learnt and Experiences Gained During Past 40 Years. S.P.E 91787, SPE International Petroleum Conference, 2004.

LAKE, L. W.;Enhanced Oil Recovery, Englewood Cliffs, New Jersey, Prentice Hall, 1989.

MIRANDA, A.C.; Formação de Emulsões no Escoamento Multifásico de Óleo e Água em meios porosos, 2010.

ROSA, A. J.; CARVALHO, R. S.; XAVIER, J.A.D.;Engenharia de Reservatórios de Petróleo, Editora Interciência, 2006.

Van Meurs, P.\& van der Poel, C.; A theorithical Description of Water Drive Process Involving Viscous Fingering. Petroleum Transactions, AIME , 103-112, 1958.

ZAITOUN, A., KOHLER, N., GUERRINI,Y.; Improved polyacrylamide treatments for water control in producing wells. Journal of Petro. Tech., p. 862-867 (1991). 